\title{
Book Discussions: A Novel Format for Transporting Classic Works into Present-Day Phonetics Research
}

Dear readers of Phonetica: your ideas, contributions, and suggestions have helped the "book notice" section in Phonetica to develop very well over the past 2 years. Outside of the 2 special issues since 2014, book notices have become an integral part of every issue. This is also true of the present one, which, like issue 73/2 before, even includes 3 of them. Given this success story, we have recently decided together with the journal's editorial board to make this section still more attractive and inspiring by offering our authors and readers an innovative new type of book review.

Our new type of book review is timely and relevant for a number of reasons. While many of us view the financial and structural problems of phonetic institutes around the world with (justified) concern, we should not forget that phonetics is indeed a thriving field of research. This is all the more true since the production and perception of prosody, its complex interaction with sound segments, and the tremendous phonetic variability in everyday communication have become key topics. The 2 recent special issues in Phonetica on Slavic prosody and the comparison of first- and secondlanguage production and perception reflect these developments very well. The same applies to the current special issue under development, on constancy and variation in speech, whose guest editors are C. Graham and B. Post from Cambridge University (please check the journal's homepage for further details). Over and above the field's internal achievements and advancements, issues of language acquisition, change, and death in the context of globalization or migration, as well as the growing demand for high-quality digital communication channels and properly functioning, socially sensitive human-machine interfaces have become major external growth accelerators for phonetic research. These growth factors have stimulated a new level of practiced multidisciplinarity. It is this multidisciplinarity that is likely responsible for a good deal of the institutional issues that we face in the field. Yet, it would be wrong to generalize these problems to the field's subject matter. Phonetic research and the questions it addresses are certainly not on the decline; on the contrary, their importance is increasing, and the same applies to the number of researchers who are engaged with phonetic questions even if they originally started their academic careers in a different field.

However, while we have a lot of good reasons to be optimistic about the future of phonetics - and Phonetica's new type of book review is one contribution to actively shape it - the increasing numbers of phonetic researchers and conferences all over the world, in combination with their increasing multidisciplinarity, also have a downside. They make it successively harder also for established experts to keep track of the latest publications in the field, and, yet more critically, there is a risk especially for early-stage

\section{KARGER @ 2017 S. Karger AG, Basel}


researchers that those seminal books that once laid the foundations for phonetics in the 19th and 20th century get buried under a flood of new journal and conference papers, i.e. those forms of publications that replaced books as the traditional publication standard quite a while ago already. Many would probably agree that the seminal books of our field are consequently less read and cited, and fewer and fewer people know hardly much about them except for their key findings and statements. Moreover, many of these books still contain valuable in-depth descriptions of forms and functions, or point out directions for follow-up research, that have largely gone unnoticed by the phonetic community. In addition, many of our seminal books have been written in languages other than English; and since English has prevailed as the language of science, these books are nowadays simply not accessible anymore to a large readership.

In summary, we still see a lot of unexploited potential in our seminal books from the 19th and 20th century to inspire researchers, stimulate ideas and discussions, discuss old observations in the light of new corpus-based or instrumental empirical evidence, compare old books to new books on similar topics, or simply make us rethink and question the assumed-to-be solid truths of our field.

For these reasons, we are pleased to introduce a new submission type in the present issue: the book discussion. We would like to invite and encourage all friends of the seminal classics of our field to submit their book discussions to Phonetica. Unlike book notices, book discussions are not mere assessments or recommendations of books. They also go well beyond summarizing the book's content. In fact, authors of book discussions should not spend more than half of the text on the content summary. The main part of the text should be dedicated to some kind of call to action that, for example, can be based on one or more of the following points:

- Relate seminal books to recent publications in order to make empirical or methodological developments explicit and, on this basis, suggest future research directions, also potentially controversial ones that depart from currently established paths;

- Critically discuss in the light of state-of-the-art methods or empirical evidence (including evidence from one's own research) findings, observations, or claims that were made on the basis of outdated instrumental or experimental methods or that were simply not measureable at all and thus had to remain at the level of subjective observations or claims;

- Point the scientific community to largely overlooked findings, observations, or claims, and thus encourage readers to revisit them;

- Take up findings or observations and develop them further into new ideas and perspectives for follow-up studies that are relevant and original but have not been conducted as yet.

Given these points, it is obvious that book discussions should not just prevent us from reinventing the wheel, although this is indeed meant to be one of their tasks. Over and above that, the new type of book review is supposed to mount new wheels on a classic car (i.e. a seminal book and its ideas) to deliver new insights and directions for research. Unlike the traditional type of book notices, book discussions also allow bringing in one's own research findings and papers, making them potentially more worthwhile for some authors to write than traditional book notices; and compared to the latter, their stronger focus on research findings and perspectives will certainly attract more citations than do traditional book notices.

Two examples of book discussions are already included in this issue, and we are very grateful to Daniel Recasens and Plinio Barbosa for their initiative and pioneering 
work. Recasens discusses a book by George Millardet (1910) in which the author presents and explains consonant and vowel insertions in Gascon, a dialect of Occitan spoken in South Western France. Recasens' book discussion provides its readers with selected examples of these insertions and, on this basis, outlines how modern (trans)segmental coarticulation theories or models would interpret Millardet's data and which challenges or opportunities for further research arise from these interpretations. In the latter context, Recasens stresses in particular that Millardet's data call for a better understanding of how multiple simultaneous (e.g., anticipatory and carryover) coarticulation effects combine and affect the timing and shape of articulatory gestures in different contexts. Recasens further suggests that it would be worthwhile to examine examples like those reported by Millardet in terms of magnetometric or ultrasound measurements, and, given the fact that Millardet's data result from auditory analyses, to also not forget analyzing in more detail how these measurements are related to speech perception and the emergence of sound change. This integrative methodological approach "should render coarticulation and gestural models more realistic than they are at the present time" (p. 253).

Barbosa embeds his detailed discussion of Raymond H. Stetson's seminal book on motor phonetics in a short overview of the previous research on speech breathing. This is because Stetson's book is, according to Barbosa, far more than the defense of the syllable as a basic unit in speech production, for which it is best known. Compared to that, the light the book sheds on "the role of breath groups in organizing the speech chain has often been neglected so far" (p. 256). Barbosa identifies the hierarchical organization of timing as one of the major tenets of Stetson's thinking about breath groups. On this basis, several avenues for further research on the organization and realization of breath groups in speech are pointed out. These avenues have been prepared by new developments in time series analyses and instruments like the respiratory inductive plethysmograph that is able to measure breathing patterns in a noninvasive yet far more precise and efficient way than the old techniques used by Stetson. Another avenue relies on the rapid accumulation of knowledge in the area of (social) prosody. In fact, Barbosa sees a lot of potential in the fact that Stetson's book "is relatively unknown to the majority of the students in prosody [but] could help them to develop new insights" into experimental design, statistical techniques, and breathing processes in general ( $\mathrm{p}$. 258). In the opposite direction, there is also much unlocked potential in combining - in a quantitative approach - Stetson's ideas about breathing and the perturbation technique he used with the currently intensively studied factors of phonetic variation such as speech rate, speaking style, utterance complexity, and idiosyncratic features like sex, age, and physical condition.

To conclude with some technical information, book discussions are supposed to have the same short, concise, and reader-friendly format as Phonetica's regular book notices, although they can be a little longer (i.e. up to 2,500 words) and may also include a few figures. Authors may use a reasonable number of headings to structure their text in book discussions, but should refrain from using more than 1 level of subheadings. Submissions should be double-spaced and start with specifying, above the main text, the bibliographic data of the discussed book followed by the book discussion author's name, affiliation, and e-mail address. There is no abstract. Footnotes must be avoided. In all other respects, the usual guidelines for manuscripts to be published in Phonetica apply to book discussions as well. This includes figures and the journal's citation format. For further information, please see https:/www.karger.com/Journal/ Guidelines/224275. 
We are sure that many further book discussions will follow after those of Recasens and Barbosa, and we look forward to receiving your submissions through Phonetica's online submission platform! Please indicate in the title of your submission that it is a book discussion. If you have any suggestions for books to be discussed or are not sure whether or not a book you would like to discuss is relevant, please do not hesitate to get in touch with the Editor-in-chief of Phonetica, Catherine Best, or the journal's book review editor, Oliver Niebuhr. In the meantime, we hope you enjoy reading the first 2 book discussions that are included in the present issue.

Oliver Niebuhr

Catherine Best 